\title{
Some Social Implications Drawn from Recent Publications in the BJSTR, by Researchers' Origin Countries
}

\author{
Ki-Hoon Jun* \\ Latin American Studies, South Korea
}

*Corresponding author: Ki-Hoon Jun, Graduate School of Latin American Studies, Hankuk University of Foreign Studies, South Korea

\section{ARTICLE INFO \\ Received: 崖 February 11, 2019 \\ Published: 幽 February 20, 2019}

Citation: Ki-Hoon Jun. Some Social Implications Drawn from Recent Publications in the BJSTR, by Researchers' Origin Countries. Biomed J Sci \& Tech Res 14(5)-2019. BJSTR. MS.ID.002618.

Keywords: Social Context; Research Interest; China's Dementia; Korea's Diagnosis Orientedness; Breast Cancer in Africa

\author{
ABSTRACT
}

In this short-communication, I briefly summarize the subject-selection pattern of researches published on the BJSTR since the late 2016. While most publishing researchers came from Middle-East, Africa, East Asia and Eastern Europe, they tended to focus on a specific theme or phenomenon, by region. First, recent African publishers tended to focus on breast-disease; however, based on other literature on other regions, this does not seem to be product of African region's special feature, nor genetic idiosyncrasy of African women - their genetic diversity is even wider than any other part of the world. In the case of China, its researchers tended to focus on plant substances and brain symptoms, due to its emphasis on traditional medicine and recent growing concerns on elderly's mental health. Meanwhile, Korean researchers tended to prioritize on overcoming chronic diseases, with more emphasis on the early diagnosis over late treatment and focus on transformation of human-body organs. With those examples, it is shown how different societies tend to form researchers' collective interests.

\section{Introduction}

When looking at since-2016 articles published in the BJSTR, there seem relatively few studies from Western Europe, North America and Australia; it might sound not very good not to have those seemingly leading countries in biology and medicine, not every aspect is negative - with more concentration of researches from the third world, it could provide alternative viewpoints as supplements to the approaches pursued by other journals in the same field. Given that, in this paper I show those third regions' certain patterns of subjects, as reflection of social situations faced by different regions, with analyses on articles published on the BJSTR from the late 2016 until the end of 2018.

\section{Breast-Cancer Problem in Sub-Saharian Africa}

On the publications for BJSTR, most researches from Subsaharian African tended to focus on breast cancer of women [1-5] , only except two Nigerian studies about food-safety system [6,7]. This is not of a mere coincidence, according to Kantelhardt \& Frie [8]'s analyses in recent emergence of breast-cancer in Sub-Saharian
Africa. Based on meta-analyses for literature until 2016, they reveal the followings.

1) Citing the GLOBOCAN database [8], they found that annually almost 100,000 cases of breast cancer break out in this region; meanwhile, they also indicated that its curing depends on early diagnosis, far more than in most other regions and usual cases.

2) However, citing report of Lancet Global Health [8], they found no significant effect of social backgrounds(e.g. race), on the occurrence of breast cancer.

3) According to the same article, neither the genetic idiosyncrasy of the African race is the key factor; its impact on the stage-progress has been argued by some, but none of them was proved. Rather, more evidences support the role of increasing life expectancy and rapid urbanization in this region - actually, the cancer is the disease more spread in advanced countries [9]. 
4) Taken all together, the key explanation for Sub-Saharan Africa's breast-cancer comes from recent and relatively-late substantial development of this region's societies, rather than Africa's own genetic features or social-norm constraints [2].

On the other hand, in a more recent report published by 2017, Vanderpuye et al. [10] reveal severely lower survival rate of breastcancer in Sub-Sahararan countries, compared to North-Africa. This feature could imply that the more fragmented and sparse population-structure in Sub-Saharan countries could be a major barrier to nationwide countermeasure against the soaring breastcancer rate. Here, it should be noted that North African countries are not characterized by the extreme diversities in terms of language and race, alike others as Nigeria or Tanzania. Furthermore, (Table 1) confirms that North African countries are more centralized in population distribution - , which means that investing caring center only on the largest city or capital city can help a lot in those countries, while in Sub-Saharan countries the same policy serves to only a fraction of population. For example, Algeria is economically less developed than South Africa, but enjoys higher rate of breastcancer survival. This example shows that Sub-Saharan Africa would have more difficulty in dealing with nationally-spreading breastcancer problem mainly due to social fractionalization, rather than mere underdevelopment of economy and infrastructure.

Table 1: Centralization degree in North Africa and Sub-Saharan Africa, in terms of population distribution.

\begin{tabular}{|c|c|c|c|c|}
\hline & \multirow{2}{*}{ Countries } & \multicolumn{2}{|c|}{ Total population available by 2017} & \multirow[b]{2}{*}{ B/A } \\
\hline & & Whole country $(=A)$ & The Largest City (=B) & \\
\hline \multirow{3}{*}{ North Africa } & Algeria & $41,320,000$ & $3,500,000$ & 8.47 \\
\hline & Tunisia & $11,530,000$ & $2,700,000$ & 23.42 \\
\hline & Libya & $6,380,000$ & $1,160,000$ & 18.18 \\
\hline \multirow{3}{*}{ Sub-Saharan Africa } & Nigeria & $191,000,000$ & $21,000,000$ & 10.99 \\
\hline & South Africa & $56,720,000$ & 433,688 & 0.76 \\
\hline & Tanzania & $57,310,000$ & $4,370,000$ & 7.63 \\
\hline
\end{tabular}

China: Focusing on Plant Substances and Brain Symptoms

Meanwhile, all Chinese researches since 2017 focused on the chemicals and plant substances [11-17] or brain disorders [18,19]. Those dominant trends, in fact, have something to do with China's social trends. First, the international media like Lancet, since 2016, have indicated that in China the aged suffers more than in most advanced or developing countries; by 2014 its dementia patients takes over $25 \%$ of all patients from the world over $140 \%$ increase over the last 20 years [20]. The thing is, unlike the other developing countries duri'0ng the last decade, China also suffered the collapse of traditional family culture prioritizing the care on the elderly. "The health needs of older people in China challenge the country's health and social care system seriously-and unprecedentedly. According to the China Health of Retirement Longitudinal Study 2015 report, a third of Chinese people aged 60 years or older have severe depression, and the prevalence of hypertension and diabetes is $53.6 \%$ and $23.9 \%$, respectively, in this population. Furthermore, 500000 elderly people go missing in China per year, around 25" [21]. In the article above, it is worth to note that the majority of elderly people's situation described above are about mental syndrome, rather than physical ones. At the same time, the article also indicates that the elderly in China these days are excluded from traditional familial care. As Jane Qiu quoted in the same article "Care for China's elderly people can no longer largely count on families". In my view, those emotional and mental problems suffered by the elderly nowadays in China are counted on the research trend in this journal. On the other hand, the emphasis on the plant substance seems to have something to do with the recent Chinese government's emphasis on the health-care food and its production system [22].

However, those researches are not enough to cover all the main health-problems remaining serious in China. According to a Korean institute's study about Chinese medical tourists, Chinese people are genetically prone to lactose-intolerance Mediterranean anemia and glucose; and because those health problems are little cared under Chinese current system, still its many patients depend on foreign service, including those from its neighbor-country South Korea [23].

\section{Korea: Diagnosis Rather Than Treatment}

Besides, Korean researchers since 2017 have focused on the improvement of diagnosis methodology as well as transformation of bodily organs rather than dealing with them as they are [24-26]; and another focus in their researchers have been the reproduction of human organs [26-28]. Those trends could be explained by several factors. First, while temporary diseases (e.g. cold) are almost conquered by medical technology's advancement, still chronic diseases are of main concerns for Korean's health [29]; and for those chronic diseases, the early discovery is always critical. On the other hand, although having suffered accidents like Hwang scandal of data manipulation for stem-cell development, Korea's genetic technology keeps progressing, and now medical scientists seem confident with organ's transformation and artificial development.

\section{The Rest}

When it comes to Japanese researches' recent publications in the BJSTR, they tended to address local situations of health-care 
system and social programs dealing with it [30-32]. However unlike the aforementioned cases, the Japanese case cannot be surely interpreted as reflection of social circumstance; at least, there is no signal about increasing social reflection about Japanese medic-care system in recent days, and Japanese medical-science is covering various parts of fields without one-sidedness. Lastly, while the majority of most researches came from Eastern-European or Middle-East researchers, they are not showing any specific trend in subject selection. Nevertheless, to conclude, the research tendencies from Africa and East Asian countries clearly confirm that different societies have specifically different subject priorities over time, with strong linkages with social backgrounds.

\section{References}

1. A De Almeida, Eliza Maria de Freitas Rangel, Kelly Cristina Reis, Ana Silvia Diniz Makluf, Soraia Martins de Araujo, et al. (2018) Multidisciplinary Approach in Breast Cancer. Biomed J Sci Tech Res 5(4): 10-13.

2. S Rafique, Z Waseem, F Sheerin (2018) Breast Cancer Awareness, Attitude and Screening Practices Among University Students: Intervention Needed. Biomed J Sci Tech Res 4(5): 4-7.

3. RR Malla (2017) Emerging Diagnostic and Prognostic Biomarkers of Triple Negative Breast Cancer. Biomed J Sci Tech Res 1(3): 561-565.

4. Azamris (2017) Prognosis Comparison Molecular Subtype Breast Cancer between Young and Adult Women at General Hospital Dr. M Djamil Padang. Biomed J Sci Tech Res 1(6): 1-9.

5. A De Almeida, Alexandre de Almeida Barra, Elyonara Mello de Figueiredo, Giselda Ribeiro da Silva, Raíssa Fernada Rodrigues Ribeiro, et al. (2018) Influence of Physical Activity on the Quality of Life of Breast Cancer Patients. 10(3): 1-4.

6. A Anani, Alex Ajeh Enuneku, Ikpomwonsa Bright Omorhienrhien, Lawrence Ikechukwu Ezemonye (2019) Potential Carcinogenic Risk Evaluation of $\mathrm{Pb}$ in Selected Canned Foods Obtained from Superstores in Nigeria. 13(3): 1-4.

7. KA Ismail, Ahmed Mahmoud Khalifa, Farah Anjum Ansari, Hasnaa A Abouseif (2018) Assessment of the Knowledge, Attitude and Practice about Food Safety among Saudi Population in Taif. Biomed J Sci Tech Res 8(2): 4-10.

8. EJ Kantelhardt, KG Frie (2016) How advanced is breast cancer in Africa? Lancet Glob Heal 4(12): e875-e876.

9. (2011) NOP: League table shows Denmark has world's highest cancer rates - Oncology new. World Cancer Research Fund Press Release, UK.

10. V Vanderpuye, Grover S, Hammad N, PoojaPrabhakar, Simonds H, et al. (2017) An update on the management of breast cancer in Africa. Infect Agent Cancer 12(1): 1-12.

11. J Nasar (2018) Perceiving Agriculture in China. Biomed J Sci Tech Res 8(1): 8-10.

12. OZ Olatunde, Y Yang, J Yong, C Lu (2019) Advance of the Chemical Components and Biological Activities of Ajuga Decumbens Thunb. Biomed J Sci Tech Res 5(4): 1-8.

13. H Li, Wei Tian, Guangzhou Song, Mengyao Ding, Honggen Yi, et al. (2019) Platelet Adhesion Comparison of Silk Fibroin Dissolved by Different Solvents. Biomed J Sci Tech Res 5(4): 2018-2020.
14. H Song, B Li (2017) Beneficial Effects of Collagen Hydrolysate: A Review on Recent Developments. Biomed J Sci Tech Res 1(2): 458-461.

15. YW Hung, CS Tsung, CF Chiu, CC Chiu, HW Chiu, et al. (2019) Study of Phototoxicity of LED Light for Colon Cancer. Biomed J Sci Tech Res 13(4): 13-15.

16. Y Wei, Fong In Chou, Wen Sheng Huang, Ko Han Lin, Po Shen Pan, et al. (2019) Boron Neutron Capture Therapy: A New Generation of Targeted Charged-Particle Radiotherapy. Biomed J Sci Tech Res 13(1): 1-3.

17.W Zhao, ZL Li (2018) Gastric Calcifying Fibrous Tumor: A Clinicopathologic Analysis of 2 Cases. Biomed J Sci Tech Res 12(2): 1-3.

18. Chenghui Yang, Xirui Guo, Jia Chen, Bo Zhou, Wei Wu (2018) Epidemiological study of Dementia in China, Japan, America and Europe. Biomed J Sci Tech Res 5(2): 1-3.

19. JL Fang, Xiao Jiao Li , Chun Hong Liu, Peijing Rong (2018) Case Report is Transcutaneous Vagus Nerve Stimulation Helpful in the Treatment of Treatment- Resistant Depression? A Case Presentation and Discussion of Clinical Efficacy. Biomed J Sci Tech Res 5(2): 1-2.

20. A Yan (2018) Will China be able to care for millions of dementia sufferers? South China Morning post.

21. The Lancet (2016) Ageing in China: a ticking bomb. Lancet 388(10056): 2058.

22. Cho Min (2019) The market trend on dietary supplement in China (In Korean: [yumang] jungguk geongangbojosikpum sijangdonghyang) Overseas FDI Network of Kotra, Korea p. 1-9.

23. J Kim (2012) Analysis of Chinese patients' use of Korean medical-care service (in Korean: jungguginhwanja gungnae uiryoseobiseu iyong paeteon bunseok).

24. H Jung, L Biomed, T Res, I Jeong, H J Lee (2018) Psoriasis Skin Models as Promising Tools in Psoriasis Research. Biomed J Sci Tech Res 2(3): 8-11.

25. J Kim, S Jeong, J Tang, E Lee (2018) Is Prefilled Contrast Agent Effective in Timesaving and Patient Safety. Biomed J Sci Tech Res 5(4): 1-5.

26. EJ Lee, BH Jin (2018) Characterization of Polyacrylamide Hydroxyapatite (PAHA) Disc Demineralization Invitro based on Optimized Areal Surface Profiling and Topography Analysis using Confocal Laser Scanning Microscopy. Biomed J Sci Tech Res 2(3): 1-7.

27. S H Yang (2018) Coating of Single Cells towards Biomedical Applications. Biomed J Sci Tech Res 3(3): 10-12.

28. YW J, MG Chung (2018) Bioabsorbable Bone Plates Enabled with Local, Sustained Delivery of Bmp2 for Bone Regeneration. Biomed J Sci Tech Res 2(3): 1-8.

29.J Chae (2016) $30 \%$ of Koreans are suffering the chronical disease. Hankuk Ilbo.

30. Y Nagaya (2018) A Review of Factors Affecting Nursing Turnover in Japan. 5(4): 1-9.

31. T Tsujiguchi (2018) The Transition of Nuclear Disaster Medical System in Japan; the Change after Fukushima Daiichi Nuclear Power Plant Accident and the Activities of Hirosaki University. Biomed J Sci Tech Res 8(3): 8-10.

32. M Ogawa, R Matsumoto, A Imai (2018) Institutional Review Board Roles and Functions to Conduct Clinical Trials at a Medium-Sized Regional Hospital, Japan 2(1): 1-2. 


\section{ISSN: 2574-1241}

DOI: 10.26717/BJSTR.2019.14.002618

Ki-Hoon Jun. Biomed J Sci \& Tech Res

(c) (i) This work is licensed under Creative

Submission Link: https://biomedres.us/submit-manuscript.php

$\begin{array}{ll}\text { BIOMEDICAL } & \text { Assets of Publishing with us } \\ \text { RESEARCHES } & \text { - Global archiving of articles } \\ \text { - Immediate, unrestricted online access } \\ \text { ISSN: 2574-1241 }\end{array}$

